\title{
FIBROMA IN THE HIND LIMB OF A LION
}

\author{
V.S.C. Bose ${ }^{1}$, I. Nath ${ }^{2}$, S.K. Panda ${ }^{3}$, A.T. Rao ${ }^{4}$ and R.K. \\ Samantray ${ }^{5}$
}

${ }^{1}$ Head, Department of Surgery, ${ }^{2}$ Assistant Professor, Surgery, ${ }^{3}$ Assistant Professor, Pathology, ${ }^{4}$ Emeritus Scientist, Pathology, Orissa Veterinary College, Bhubaneshwar, Orissa 751003, India. ${ }^{5}$ V.A.S., Nandankanan Zoo, Orissa, India.

Tumors of various types have been reported in tigers. This paper describes a successful radical excision of a fibroma in the hind limb of a lion.

A male lion, 10 years old and weighing about $160 \mathrm{~kg}$ at Nandankanan Zoo developed a growth at the lateral aspect of its right thigh region. The growth increased in size measuring about $10 \times 5 \mathrm{~cm}$ in a month. The lion was seen rubbing the mass against hard objects which resulted in bleeding. So it was decided to examine the growth after restraining it in a squeeze cage.

The lion was shifted to a squeeze cage from its enclosure by luring with a beef bait and was transported to the zoo hospital. While shifting the lion for examination, the outer protruded portion of the growth peeled off due to friction of the limb with the bars of the squeeze cage resulting in bleeding. Forcible gauze pressure and adrenaline spray stopped bleeding. On palpation, the growth was felt to be hard, extending to the surrounding subcutaneous area at a radius of $5 \mathrm{~cm}$ (Fig. 1). Hence, it was decided to excise the mass from the underlying area along with its base. The next day, a mixture of $200 \mathrm{mg}$ of xylazine hydrochloride and 400mg of ketamine hydrochloride was injected intramuscularly. The lion was recumbent within 10 minutes. A swab was taken from the site for sensitivity test. After routine surgical toilet radical excision of the mass was carried out after making elliptical skin flaps (Fig. 2). The wound was closed after irrigating with Providone Iodine lotion. Intramuscular Taxim $2 \mathrm{~g}$ b.i.d, was continued for seven days. Thereafter the stitches shed off due to self-mutilation. It was decided to treat the lesion as an open wound. The antibiotic was changed to parenteral gentamycin sulphate $600 \mathrm{mg}$ along with topical spray to the wound basing on the sensitivity test. The wound healed to a small scar in 10 days. The animal was released to its enclosure after five days.

On histopathological examination, the mass revealed to be a

fibroma characterized by interlacing bundles of fibrous connective tissue arranged in all directions with spindle shaped nuclei of fibroblast.

In this case, the lion might have mutilated the wound because of irritation in the healing process. The sensitive topical and parenteral antibiotic helped to control infection. As fibroma is a benign tumor, radical excision from its base and surrounding tissue resulted in an uneventful recovery.

\section{Acknowledgement}

Authors are thankful to the Director of the Nandankanan Zoo for according permission to do the work.

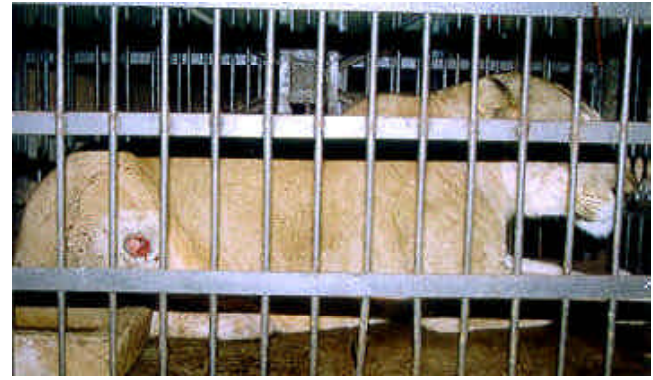

Figure 1. Photograph showing portion of tumor mass in the Lion after shedding off the outer protruded portion

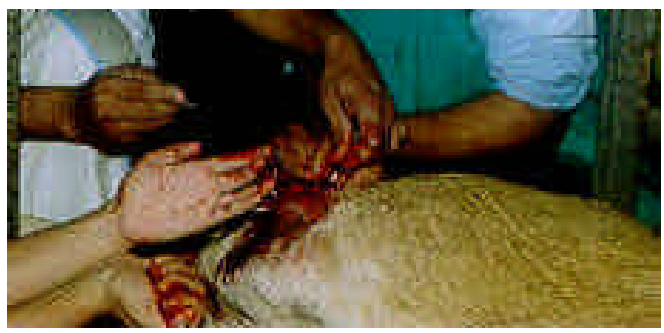

Figure 2. Photograph showing radical excision of the mass 